\title{
Prehospital emergency treatment of palliative care patients with cardiac arrest: a retrolective investigation
}

\author{
Christoph H. R. Wiese • Utz E. Bartels • \\ York A. Zausig • Jochen Pfirstinger • \\ Bernhard M. Graf • Gerd G. Hanekop
}

Received: 19 June 2009 / Accepted: 15 September 2009/Published online: 8 October 2009

(C) The Author(s) 2009. This article is published with open access at Springerlink.com

\begin{abstract}
Background Today, prehospital emergency medical teams (EMTs) are confronted with emergent situations of cardiac arrest in palliative care patients. However, little is known about the out-of-hospital approach in this situation and the long-term survival rate of this specific patient type. The aim of the present investigation was to provide information about the strategic and therapeutic approach employed by EMTs in outpatient palliative care patients in cardiac arrest. Methods During a period of 2 years, we retrolectively analysed emergency medical calls with regard to palliative care emergency situations dealing with cardiac arrest. We evaluated the numbers of patients who were resuscitated, the prevalence of an advance directive or other end-of-life protocol, the first responder on cardiac arrest, the return of spontaneous circulation (ROSC) and the survival rate.
\end{abstract}

C. H. R. Wiese $(\bowtie) \cdot$ Y. A. Zausig • B. M. Graf

Department of Anaesthesiology, University of Regensburg,

Franz-Josef-Strauß-Allee 11,

93053 Regensburg, Germany

e-mail: christoph.wiese@klinik.uni-regensburg.de

U. E. Bartels

Department of Anaesthesiology,

University of Uem,

Uem, Germany

J. Pfirstinger

Department of Internal Medicine, Outpatient Palliative Care Team

“ABRIGO”, University of Regensburg,

Regensburg, Germany

G. G. Hanekop

Department of Anaesthesiology, Emergency and Intensive Care

Medicine, University of Goettingen,

Goettingen, Germany
Results Eighty-eight palliative care patients in cardiac arrest were analysed. In 19 patients (22\%), no resuscitation was started. Paramedics and prehospital emergency physicians began resuscitation in 61 cases $(69 \%)$ and in 8 cases $(9 \%)$, respectively. A total of 10 patients $(11 \%)$ showed a ROSC; none survived after $48 \mathrm{~h}$. Advance directives were available in $43 \%$ of cases. The start of resuscitation was independent of the presence of an advance directive or other end-of-life protocol.

Conclusions Strategic and therapeutic approaches in outpatient palliative care patients with cardiac arrest differ depending on medical qualification. Although many of these patients do not wish to be resuscitated, resuscitation was started independent of the presence of advance directive. To reduce legal insecurity and to avoid resuscitation and a possible lengthening of the dying process, advance directives and/or "Do not attempt resuscitation" orders should be more readily available and should be adhered to more closely.

Keywords Emergency medical care $\cdot$ Palliative medical care - Unresponsiveness · Palliative care patient .

Cardiac arrest $\cdot$ Resuscitation $\cdot$ End-of-life decision

\section{Background}

In outpatient palliative care patients who are in advanced stages of their cancer disease, acute situations often arise [1, 2]. In fact, of all emergency medical calls made to which emergency medical teams (EMT) are dispatched, approximately $3 \%$ involve emergent situations in palliative care patients [3-5]. In about $60 \%$ of these cases, cardiac arrest is mentioned in the EMT report [6]. This is of great concern, as such situations are often linked with poor outcomes after 
resuscitation [6-9]. As a result, it is very important in these cases for providers to be aware of the patients' will, especially when their desires are stated in an advance directive or a "Do not attempt resuscitation" order (DNAR order). In the setting of an emergent situation in a palliative care patient, EMTs are often alerted but are not given information concerning the patients' wishes with regard to extraordinary measures taken to preserve their life. This leads to the resuscitation of palliative (patients in an advanced stage of their disease in which no curative therapy is possible any more) care patients during cardiac arrest; a situation that is known to result in a poor prognosis. This is particularly problematic in this population of patients because even though the patients' physical symptoms can be aggressively treated, emergency medical treatment often extends the dying process of the patient [10]. Advance directives and DNAR orders are an important expression of the patients' wishes concerning the course of long-term therapy. In 2003, a decision made by the Supreme Federal Court of Justice in Germany underlined the importance of advance directives in deciding therapeutic measures [11]. In Germany, however, patients' participation in therapeutic decisions at the end of life is still very much lacking $[12,13]$. In this regard, abstaining from intervention in accordance with the patients' will may be appropriate. Otherwise, in cardiac arrest situations, prehospital emergency physicians (EP) or paramedics' treatment can also result in "Action" or "Non-Action" with a possible extension of the dying process [5].

In Germany, prehospital emergency medical systems are based on an integration of EPs. One element of note is that qualified EPs and paramedics are always on ambulances together [14]. Such EPs are often times better equipped to make decisions than a paramedic, ambulance staffer or emergency medical technician, especially with regards to end-of-life decisions in palliative care patient who has undergone cardiac arrest. In every domain of out-ofhospital emergency medical treatment of palliative care patients, the importance of the EMT's competence in palliative medical care is high [5]. In Germany, EPs are free to decide whether to start measures attempting resuscitation. Therefore, they do not always have to start trying resuscitation in patients with cardiac arrest. Furthermore, they can stop resuscitation in according to evidencebased guidelines (for example concerning to the European Resuscitation Council from 2005) and in due to the patients prognosis and their comorbidities. The EPs are entitled to take all decisions during prehospital emergency care.

The aim of the present investigation was to determine what the treatment was of unresponsive palliative care patients in an advanced stage of their cancer disease during cardiac arrest situations. In addition, the purpose of this investigation was to discover how EPs treat advance directives and what decisions they make concerning resuscitating patients. Secondarily, the poor prognosis of palliative care patients after return of spontaneous circulation (ROSC) during cardiac arrest is shown retrolectively.

\section{Methods}

In a multi-centre investigation, we retrolectively examined in all EP-based resuscitations during cardiac arrest situations of out-of-hospital palliative care patients. We investigated only those emergency medical cases that involved palliative care patients in which no curative therapeutic approach could be applied. During the defined period of 2 years (October 2005 to September 2007), we examined all emergency medical care contacts across four emergency medical care services. This investigation is part of a prospective analysis of all emergency medical care situations in palliative care patients during the defined period [5].

For this purpose, we used standardised emergency documents (for example, DIVI 2003 (MIND 2) EPRO 4.2-4-NDS). The survival rate after the cardiac arrest situation was determined by referring to the patients' in-hospital documents until the patient was dismissed from hospital or died in hospital.

All patients with the primary diagnosis "unresponsive palliative care patient" were retrolectively investigated (unresponsive - not responding patient to some influence or stimulus). Data concerning hospitalisation, length of inhospital stay, date of death and/or date of discharge were measured from in-hospital claims.

The following demographic and descriptive data of the patients were gathered:

- Total number of all emergency calls in palliative care patients

- Total number of all cases with the primary diagnosis "unresponsive patient" and palliative care patient with the diagnosis "cardiac arrest"

- Age and gender of patients

- Place of emergency medical care (for example homecare, nursing home)

- Availability of an advance directive and/or a DNAR order

The defined retrolectively investigated study points were:

- Patient being/not being resuscitated.

- Resuscitation start performed by lay people/paramedics or EP

- Number of patients with ROSC after cardiac arrest

- In-hospital treatment of the patients after confirming ROSC

- Survival rate less or longer than $24 \mathrm{~h}$

- Presence of an advance directive or DNAR order that demonstrated the patient's wishes 
In the present investigation, patients only included were those who conformed to the defined criteria (unresponsive palliative care patient) and those whom all the collected parameters were comprehensively documented.

Data was evaluated with MS Excel 2003 (Microsoft Inc., United States) and SPSS 16.0 (SPSS Inc., Chicago Ill., United States). Because of the descriptive and retrolective character of the present investigation, no statistical analysis was necessary. Based on the declaration of Helsinki, data was collected anonymously [15]. The ethical regulations for investigation of personal data were observed. The investigation was approved by the local ethics committee. Inferences about individuals (e.g. patients, care-giving relatives and emergency medical service staff) were not possible.

\section{Results}

Over the defined 2-year period, 113 emergency medical contacts concerning unresponsive patients were detected. A total of 361 patients with the criterion advanced cancer patient were found [5]. Seven patients had to be excluded due to incomplete emergency medical documents. Therefore, 106 patients were included in the present investigation ( $29 \%$ of all emergency medical cases in palliative care patients).

In the group of patients that we investigated (unresponsive palliative care patients in an advanced stage of cancer disease), the average age was 74 years (range $44-95$ years, median 75 years). A total of 50 patients (47\%) were male, and 56 were female (53\%). Eighty-five patients $(80 \%)$ stayed at home during the emergency situation, and 21 $(20 \%)$ were in nursing homes (Table 1).

Table 1 Baseline demographic and clinical characteristics of the sample

\begin{tabular}{lll} 
Characteristics & & \\
\hline Average age(range; year; $n=106)$ & $74(44-95)$ & \\
$\begin{array}{l}\text { Place of emergency medical care } \\
\quad(n=106 ; n(\%))\end{array}$ & $85(80)^{\mathrm{a}}$ & $21(20)^{\mathrm{b}}$ \\
$\begin{array}{l}\text { Resuscitation in patients with cardiac arrest } \\
\quad(n=88 ; n(\%))\end{array}$ & $69(78)^{\mathrm{c}}$ & $19(22)^{\mathrm{d}}$ \\
$\begin{array}{l}\text { Return of spontaneous circulation } \\
\quad \text { ROSC; } n=88 ; n(\%))\end{array}$ & $10(11)^{\mathrm{e}}$ & $78(89)^{\mathrm{f}}$ \\
$\begin{array}{l}\text { Availability of anadvance directive } \\
\quad(n=106 ; n(\%))\end{array}$ & $46(43)^{\mathrm{e}}$ & $60(57)^{\mathrm{f}}$ \\
& &
\end{tabular}

\footnotetext{
${ }^{\mathrm{a}}$ Home-care setting

${ }^{\mathrm{b}}$ Nursing home

${ }^{\mathrm{c}}$ Started

${ }^{\mathrm{d}}$ Not started

${ }^{\mathrm{e}}$ Yes

${ }^{\mathrm{f}} \mathrm{No}$
}

Cardiac arrest was found in $83 \%$ (88 patients) of all unresponsive palliative care patients. Seventeen percent (18 patients) were primarily unconscious due to other causes (acute coronary syndrome, three; opioid intoxication, two; drug intoxication (suicide attempt), one; cerebral metastasis, two; unknown reason, 10).

The following results refer to all palliative care patients with the diagnosis "cardiac arrest". In $22 \%$ of the patients ( $n=19$ patients with "cardiac arrest") no resuscitation was started by the EMT. Paramedics started or continued (for example, because basic life support (BLS) was started by the care-giving relatives) resuscitation in $69 \%$ of all cardiac arrest situations ( $n=61$ patients). Prehospital EP began resuscitation in $9 \%(n=8$ patients). EPs stopped resuscitation that had been started by paramedics in $72 \%$ of the cases $(n=44$ of all patients in which resuscitation was started by paramedics). Therefore, in $28 \%(n=25$ patients $)$ of all cardiac arrest situations, resuscitation was done by the whole EMT (EPs and paramedics). Over all, care giving relatives started resuscitation in $10 \%(n=9$ patients $)$ of all cardiac arrest situations. In $89 \%$ ( $n=8$ patients) of these situations, resuscitation was primarily continued by the EMT.

According to ROSC, $11 \%$ ( $n=10$ patients $)$ were resuscitated successfully, and $89 \%(n=59$ patients $)$ were not (Table 1).

Concerning the unresponsive patients, advance directives were found in $43 \%$ ( $n=46$ patients), while in $26 \%$ ( $n=27$ patients), no advanced directive could be found. In $31 \%(n=33$ patients), it was not known whether an advance directive existed or not. A DNAR order was not found in any case. Concerning all cardiac arrest situations, in $48 \%$ ( $n=42$ patients) of the cases concerning cardiac arrest, the palliative care patients did not wish to be resuscitated. A small percent $(2 \% ; n=2$ patients) wanted to be resuscitated, and it was not known whether the patients wished to be resuscitated in $50 \%$ of cases. In $10 \%$ (nine patients) of the cardiac arrest situations, patients were resuscitated by the EMT even though an advance directive was shown by the care-giving relatives.

An obvious dying process could be found in $31 \%$ ( $n=27$ of all patients with cardiac arrest were in the dying process, as evidenced by the following: heart rate $<30 \mathrm{bpm}$, broad complex bradycardia, blood pressure $<40$ sys, no signs of life; resuscitation theoretically necessary). Overall, death was determined in 60\% (53 patients) by the EPs because of sure signs of death or the absence of ROSC after resuscitation. Therefore, in eight patients for whom they were in the process of dying, resuscitation was started.

In total, 28 patients $(26 \%$ of all palliative care patients with the diagnosis "unconscious") were hospitalised. All 10 patients $(11 \%)$ with ROSC were transferred to the hospital. The average survival time was $3 \mathrm{~h}$ after ROSC (range 1-44 h). No patient became conscious after cardiac arrest. 
No patient left the hospital after cardiac arrest. The places where the patients with cardiac arrest died are as follows:

- Palliative care unit, two patients

- Emergency room, three patients

- Intensive care unit, three patients

- General ward, two patients

Between home-care and nursing homes, there were no statistically significant differences concerning all investigated parameters (for example, transfer to hospital after ROSC, primary start of resuscitation).

\section{Discussion}

Emergency medical care situations among outpatient palliative care patients represent about $3 \%$ of all emergency contacts [3-5]. In elderly patients with multiple comorbidities, the general rate of survival after ROSC is about $5 \%$ [7, 9]. Moreover, patients with end-stage cancer diseases have a poor prognosis concerning ROSC after cardiac arrest $[6,16]$. In accordance with other studies, we found a shortlife survival rate $(<48 \mathrm{~h}$ after cardiac arrest) of $0 \%$ (although ROSC could be determined in $11 \%$ of all integrated resuscitations) in all cardiac arrest situations in our investigation. Hence, it is not surprising that most palliative care patients with cancer diseases (more than $60 \%$ ) do not wish to be resuscitated in the setting of cardiac arrest $[6,10]$. In the present investigation, we were not able to confirm this data. Most palliative care patients had no advance directive, and none of the patients had a DNAR order. Therefore, the patients' wills and their own defined will not to be resuscitated were not unambiguously described. However, resuscitation is started mostly due to a lack of awareness by the EMT of the patients' will $[5,8]$. It appears that advance directives and DNAR orders are useful in helping patients who do not wish to engage in extraordinary measures to avoid resuscitation, aggressive medical treatment and a possible lengthening of the dying process and should be implemented into the general care of palliative patients $[8,17]$.

Concerning in-hospital cardiac arrest situations, cardiopulmonary resuscitation is implemented in most cases when a DNAR order is absent [17]. Only $5.5 \%$ of all patients who died in-hospital had an outpatient written DNAR order, which corresponds with the data of our investigation [17]. Furthermore, aggressive treatment at the end of life (e.g. intensive care, intensive chemotherapy, intensive radiotherapy and a long-term in-hospital stay) is not desired by those patients [8].

In Germany, so-called palliative crisis cards are often used to show the patients will not to be resuscitated [18]. In the present study, nine patients were resuscitated even though an advance directive was given to the emergency medical team by the care-giving relatives. It was not possible to retrolectively investigate the reasons for the decision to resuscitate the patient in the face of an advance directive. A reason for this treatment may be some insecurity on the part of the EMT staff concerning end-oflife decisions and advance directives, as has been found in previous investigations $[4,5,19]$. Most patients who had no advance directive were resuscitated during the cardiac arrest situation. Only sure signs of death were a clear indication not to start resuscitation. This kind of treatment stands in contrast to previous investigations concerning the care of an unresponsive patient with poor prognosis [20,21]. In these investigations, the authors describe that the patients will have to be honoured, and prolonging the dying process should not be the way to treat such patients [20,21].

An important aim of emergency medical care is to save lives and transfer patients to in-hospital departments for subsequent care $[22,23]$. If the patients will is unknown, resuscitation should be started by the EMT in every patient concerning a cardiac arrest situation [23]. An EP has got the possibility to decide whether resuscitation is necessary or not. This decision has to depend on the patients' comorbidities and circumstances like time after cardiac arrest without resuscitation.

Starting resuscitation in palliative care patients with cardiac arrest often seems to contradict palliative medical therapeutic approaches. Such medical contradictions become especially apparent given the fact that emergency medicine to date has not taken into account the multidisciplinary basic principles of palliative care. Therefore, the therapeutic aims of emergency medical treatment are rarely consistent with the wishes of palliative care patients. The concept of "dying with dignity" is a theoretical construct that should be taken into account in emergency medical care situations among palliative care patients [2428]. For this reason, a combination of emergency and palliative medical care would be desirable to both address the most important issues that involve therapy at the end of life and allow physicians to act more consistently with the wishes of their patients [29]. Therefore, we recommend more education in emergency medical curricula for all members of emergency medical teams (both prehospital emergency physicians and paramedics). Because of legal questions, especially in regards to emergency medical situations, such education should also address legal questions surrounding the validity of patients' advance directives and DNAR orders.

In some cases, palliative care patients with ROSC after cardiac arrest were transferred to the hospital. As seen in our results, only two patients were treated in a specialised Palliative Care Unit. Because of spontaneous breathing, the 
tracheal tube was removed after arrival at the Palliative Care Unit and symptom control was started. An earlier investigation showed that emergency medical treatment is dependent on the knowledge of the prehospital emergency physician concerning palliative care and questions concerning end-of-life situations/treatment [5, 19]. These facts must be integrated into the emergency medical curricula, as well. Concerning the present investigation, patients' wishes were not fully respected despite the evidence. As shown in an earlier study, the EPs felt insecure in end-of-life treatment and questions [5]. Because of this insecurity, they fear legal consequences when resuscitation is not started. Such characteristics depend on the expertise of the EP [5].

In a few cases, we found primary basic BLS done by the care-giving relatives. No statistically significant differences were seen in primary resuscitation rate between home and nursing home. It is possible that this measure was begun because of the psychosocial situation that arises when a caregiver is afraid that a loved one or the patient for whom he or she is responsible might die. Thus, emergency medical situations are a special situation for the caregiving relatives and professional caregivers as well [30]. Therefore, it is necessary to integrate specialised palliative care teams as early as possible to support the palliative care patient and his caregivers during the home-care situation [30]. If this were to occur, emergency medical treatment given by an EMT could be reduced [30]. Furthermore, BLS might be avoided. This fact may stop resuscitation efforts when a patient is bearing an irreversible disease and his life is ending. Furthermore, education in palliative care should be integrated into training courses for caregivers working in nursing homes.

However, as previous studies suggest, the results of the present investigation confirm that further inpatient and outpatient research concerning end-of-life care in emergency settings is recommended $[5,19,31]$.

\section{Limitations of the current study}

Some study limitations must be noted. Although the main study used a prospective design, data of the present investigation were evaluated retrolectively. Furthermore, data were evaluated based on the available data from emergency medical service teams and regular emergency medical documents. A prompt sheet for the investigation was not used. A few documents could not be included in our investigation, with the result that the number of palliative care patients with cardiac arrest may be still higher than reported in our study.

Our discussion and our conclusions are derived in the context of the German emergency medical system and are not applicable to countries that use a paramedic-based emergency medical system. However, compared with paramedics, prehospital emergency physicians may have substantially greater medical knowledge. This is of particular importance for decisions concerning initiating or stopping resuscitation efforts in the case of palliative care patients at the end of their life. The problems described here likely exist in the paramedic systems of other countries as well.

\section{Conclusions}

The data of the present investigation underscore the importance of education in palliative care and end-of-life decisions to emergency medical care providers. Moreover, DNAR orders combined with advance directives should be used to underline the patients' will to be or not to be resuscitated. Overall, more clinical investigations concerning end-of-life care and unresponsive palliative care patients in emergency medical situations are necessary.

Competing interests The corresponding author and co-authors confirm that they have no connections to any of the companies whose products are mentioned in the article, or with any company that sells competing products. The authors mention that the present investigation includes data of patients (database), which was published previously in other journal (Supportive Care Cancer, concerning the expertise of the prehospital emergency physicians who treated all palliative care emergencies; J Opioid Management, concerning the treatment of the symptom "dyspnoea" in palliative care patients). These articles were cited in the present investigation.

Authors' contributions CHRW and GGH participated in designing the study. CHRW participated in collecting and entering the data. BMG, JP, UEB, YAZ and GGH supported the editing of the manuscript. BMG co-wrote the manuscript and added important comments to the paper. All authors read and approved the final manuscript.

Acknowledgement The authors are grateful to MD A. Schultens (Department of Anaesthesiology, Emergency and Intensive Care Medicine, University of Goettingen) for his language corrections. Moreover, we are grateful to all prehospital emergency physicians of the investigated emergency departments.

Open Access This article is distributed under the terms of the Creative Commons Attribution Noncommercial License which permits any noncommercial use, distribution, and reproduction in any medium, provided the original author(s) and source are credited.

\section{References}

1. Nauck F, Alt-Epping B (2008) Crisis in palliative care-a comprehensive approach. Lancet Oncol 133:1745-1749

2. Power D, Kearney M (1992) Management of the final 24 hours. Ir Med J 85:93-95

3. Sommer J, Müller-Busch C, Flender HJ, Korth M, Bach F, Mertzluft F (2008) Palliative care patients and emergency 
medicine. Abstract Congress of the Deutschen Interdisziplinären Vereinigung für Intensivmedizin (DIVI), Hamburg

4. Wiese C, Bartels U, Ruppert D, Quintel M, Graf BM, Hanekop GG (2007) Treatment of oncology patients at the final stage of disease by prehospital emergency physicians. Anaesthesist 56:133-140

5. Wiese CHR, Bartels U, Marczynska K, Ruppert D, Graf BM, Hanekop GG (2009) Quality of out-of-hospital palliative emergency care depends on the expertise of the emergency medical team-a prospective multi-centre analysis. Support Care Cancer. doi:10.1007/s00520-009-0616-4

6. Reisfield GM, Wallace SK, Munsell MF et al (2006) Survival in cancer patients undergoing in-hospital cardiopulmonary resuscitation: a meta analysis. Resuscitation 71:152-160

7. Diem SJ, Lantos JD, Tulsky JA (1996) Cardiopulmonary resuscitation on television: miracles and misinformation. N Engl J Med 334:1578-1582

8. Tang ST, Wu SC, Hung YN, Huang EW, Chen JS, Liu TW (2009) Trends in quality of end-of-life care for Taiwanese cancer patients who died in 2000-2006. Ann Oncol 20:343-348

9. Zoch TW, Desbiens NA, DeStefano F et al (2000) Short- and long-term survival after cardiopulmonary resuscitation. Arch Intern Med 160:1969-1973

10. Georges JJ, Onwuteaka-Philipsen BD, van der Heide A, van der Wal G, van der Maas PJ (2005) Symptoms, treatment and "dying peacefully" in terminally ill cancer patients: a prospective study. Support Care Cancer 13:160-168

11. Federal Supreme Court of Justice in Germany (2003) Beschluss vom 17. März 2003- XII ZB 2/03 (OLG Schleswig, AG Lübeck); BGH: Behandlungsabbruch bei apallischem Syndrom; Zustimmung des Vormundschaftsgerichts. BGB $\S \S 1896,1901,1904$. Z Lebensrecht 2:50-60

12. Dierks ML, Seidel G (2005) An equal respect creation between physicians and patients - want to be patients really partner? In: Härter M, Loh A, Spies C (eds) Together decide-successfully act. Köln Deutscher Ärzte-Verlag, Auflage, Germany, pp S35-S44

13. Loh A, Simon D, Kriston L, Härter M (2007) Patient's participation in medical decisions. Dtsch Ä Blatt 104:A1483-A1488

14. Timmermann A, Russo SG, Hollmann MW (2008) Paramedic versus emergency physician emergency medical service: role of the anaesthesiologist and the European versus the AngloAmerican concept. Curr Opin Anaesthesiol 21:222-227

15. Salako SE (2006) The declaration of Helsinki 2000: ethical principles and the dignity of difference. Med Law 25:341-354

16. Hwang JP, Patlan J, Achaval S, Escalante CP (2009) Survival in cancer patients after out-of-hospital cardiac arrest. Support Care Cancer. doi:10.1007/s00520-009-0629-Z
17. Levin TT, Li Y, Weiner JS, Lewis F, Bartell A, Piercy J, Kissane DW (2008) How do-not-resuscitate orders are utilized in cancer patients: timing relative to death and communication-training implications. Palliat Support Care 6:341-348

18. Wiese CHR, Bartels U, Geyer A, Duttge G, Graf BM, Hanekop GG (2008) "Göttinger Palliativkrisenbogen"- the yellow card for emergency medical services. Dtsch Med Wschr 133:972976

19. Wiese CHR, Bartels UE, Graf BM, Hanekop GG (2009) Out-ofhospital opioid therapy of palliative care patients with "acute dyspnoea": a retrospective multicentre investigation. J Opioid Manag 5(2):115-122

20. Kritek PA, Slutsky AS, Hudson LD (2009) Care of an unresponsiveness patient with a poor prognosis-polling results. N Engl J Med 360:10

21. Slutsky AS, Hudson LD (2009) Care of an unresponsiveness patient with a poor prognosis. N Engl J Med 360:5

22. Burghofer K, Lackner CK (2006) What to do and not to do in emergency medicine. Notfall Rettungsmed 9:685-690

23. European Resuscitation Council (2005) European Resuscitation Council guidelines for resuscitation 2005. Resuscitation 67:S1S189

24. Chochinov HM (2006) Dying, dignity, and new horizons in palliative end-of-life care. CA Cancer J Cli 56:84-103

25. Chochinov HM, Kristjanson LJ, Hack TF, Hassard T, Mc Clement S, Harlos M (2006) Dignity in the terminally ill: revisited. J Palliat Med 9:666-672

26. Enes SP (2003) An exploration of dignity in palliative care. Palliat Med 17:263-269

27. Hack TF, Chochinov HM, Hassard T, Kristjanson LJ, Mc Clement S, Harlos M (2004) Defining dignity in terminally ill cancer patients. Psychooncology 13:700-708

28. Karlsson M, Milberg A, Strang P (2006) Dying with dignity according to Swedish medical students. Supp Care Cancer 14:334-339

29. German Medical Council (2004) Issues of the German Medical Council concerning dying patients. Dtsch Ärztebl 101:1076-1077

30. Wiese CHR, Vossen-Wellmann A, Morgenthal HC, Popov AF, Graf BM, Hanekop GG (2008) Emergency calls and need for emergency care in patients looked after by a palliative care team: retrospective interview study with bereaved relatives. BMC Pall Care 7:11

31. Beckstrand RL, Smith MD, Heaston S, Bond AE (2008) Emergency nurses' perceptions of size, frequency, and magnitude of obstacles and supportive behaviour in end-of-life care. J Emerg Nurs 34:290-300 